\title{
The potential for using a coconut shell catalyst for the selective catalytic reduction of NOx gases
}

\author{
I. Yakub ${ }^{1}$, N. M. Sutan ${ }^{1}$, Y. H. Taufiq-Yap ${ }^{2} \&$ M. S. Islam ${ }^{3}$ \\ ${ }^{1}$ Faculty of Engineering, Univerisiti Malaysia Sarawak, Malaysia \\ ${ }^{2}$ Catalysis Science and Technology Research Centre, \\ Faculty of Science, Universiti Putra, Malaysia \\ ${ }^{3}$ Department of Chemistry, Faculty of Science, \\ Universiti Putra Malaysia, Malaysia
}

\begin{abstract}
Selective Catalytic Reduction (SCR) is a promising technique in mitigating the drawbacks of combustion system. This study investigated the potential of using coconut shell activated carbon (CSAC), an abundant and inexpensive resource, as an SCR catalyst support for sustainable energy generation. Local CSAC was physically treated by co-impregnating with Copper $(\mathrm{Cu})$ and Manganese $(\mathrm{Mn})$ oxides. The modified samples were then calcined under low temperature. Properties of all three types of samples were then characterized and analysed using Temperature-Programmed Reduction (TPR), X-Ray Fluorescence (XRF) and Fourier Transform Infrared (FT-IR). Results showed that CSAC can be an effective SCR catalyst to obtain higher conversion of NOx gases into non-toxic gas.
\end{abstract}

Keywords: biomass combustion, NOx gases, SCR, Cu-Mn catalyst, coconut shell activated carbon, carbon support, low-temperature calcination, TPR, XRF, FT$I R$.

\section{Introduction}

Biomass have been converted into energy since thousands of years ago but the development of the technology for sustainable utilization of biomass did not start until 1812 when a gas company in England demonstrated the pyrolysis of biomass 
into liquid fuel [1]. The initiative was adopted to reduce the world dependency on fossil fuels. In fact, by utilizing biomass from the residues resulted from the harvesting of agricultural crops can eliminate the "food versus fuel" dilemma, reduce land filling activity and complete the lifecycle of carbon dioxide. Nowadays, the path for the conversion of biomass waste into energy is multitudinous which includes combustion, gasification, fermentation and pyrolysis.

Despite the fact that utilizing agricultural waste is greener and sustainable, there are not much fully-operated industrial scale energy generation from waste in developing countries where biomass can be abundantly available $[2,3]$. Even though the energy recovery is usually only $35 \%$ and in some cases $85 \%$, biomass combustion is the commonest route chosen by developers due to its simple process, low capital cost ( $\$ 0.19 / \mathrm{btu} / \mathrm{hr}$ compared to $\$ 0.35 / \mathrm{btu} / \mathrm{hr}$ for gasification) and availability of equipment as well as proven technology which renders comfort investment in the market [4]. However, low energy recovery adversely increase the amount of pollutants being released during combustion process especially NOx and SOx gases and volatile organic compound (VOC).

The two most prominent ways for removal of these air pollutants from combustion process are; gas cleaning technology and Selective Catalytic Reduction (SCR), with the latter being the area of interest lately because of the lower capital cost [5-10]. SCR exploits the reaction of NOx with ammonia to produce the environmentally friendly inert gas, nitrogen [5]. Many types of catalyst have been developed, tested, and used such as titanium dioxide-supported vanadium pentoxide, zeolite $\mathrm{H}-\mathrm{ZSM} 5$ and $13 \mathrm{X}-\mathrm{APG}, \mathrm{MoO}_{3} / \mathrm{TiO}_{2}-\mathrm{V}_{2} \mathrm{O}_{5}$ honeycomb monolith and various combination of $\mathrm{Pt}, \mathrm{Pd}, \mathrm{Rh}, \mathrm{Au}, \mathrm{Ag}, \mathrm{Cu}, \mathrm{Co}, \mathrm{Fe}$, In and $\mathrm{Ga}$ metals with different supports of zeolite, $\mathrm{Al}_{2} \mathrm{O}_{3}, \mathrm{SiO}_{2}$ and activated carbon [6-13].

However, metallic support can increase the bulk cost of catalyst utilization and requires high temperature, which means increased operating cost. Yang et al. [10] had reviewed on the application of various carbon as catalyst support for flue gas treatment and concluded that activated carbon can be potentially cost-effective especially if the precursor resources are abundant. Therefore, the aim of this study is to investigate the potential of using activated carbon derived from agricultural waste, particularly coconut shell, as a support for SCR catalyst by analyzing its properties through Temperature-Programmed Reduction (TPR), X-Ray Fluorescence (XRF) and Fourier Transform Infrared (FT-IR).

\section{Materials and methods}

\subsection{Samples preparation}

Three samples were used in this study: coconut shell activated carbon (CSAC), uncalcined coconut shell catalyst and calcined coconut shell catalyst. Local coconut shell activated carbon (CSAC) supplied by Robert Scientific Sdn. Bhd. (properties shown in Table 1) were used as the control samples. Some of the CSAC were physically treated by the following procedures; firstly, they were washed 
under running tap water before oven-dried for $24 \mathrm{hrs}$. CSAC samples were then soaked and stirred in the copper and manganese $(\mathrm{Cu}-\mathrm{Mn})(1: 1)$ aqueous solution for another day. The slurry was then washed using distilled water and dried at $100^{\circ} \mathrm{C}$. These samples were used as uncalcined coconut shell catalyst (UCSC). Some of the UCSC were then calcined at low temperature to observe the development of the surface upon calcination. These samples were used as calcined coconut shell catalyst (CCSC).

Table 1: Properties of CSAC obtained from supplier.

\begin{tabular}{|l|c|}
\hline \multicolumn{1}{|c|}{ Properties } & Values \\
\hline Iodine number & Min. 1050 \\
\hline Particle size (mm) & $0.59-2.38$ \\
\hline Moisture content $(\%)$ & Max. 5 \\
\hline Ash content $(\%)$ & Max. 3 \\
\hline Ball-pen hardness & Min. 98 \\
\hline Apparent density $\left(\mathrm{kg} / \mathrm{m}^{3}\right)$ & $450-520$ \\
\hline BET surface area $\left(\mathrm{m}^{2} / \mathrm{g}\right)$ & $1100-1250$ \\
\hline $\mathrm{pH}$ & Alkaline \\
\hline
\end{tabular}

\subsection{Characterization and analysis of CSAC, UCSC and CCSC properties}

In order to evaluate the potential of CSAC as SCR catalyst, CSAC, UCSC and CCSC samples were analysed using three techniques; X-Ray Fluorescence (XRF), Fourier Transform Infrared (FT-IR) and Hydrogen Temperature-Programmed Reduction $\left(\mathrm{H}_{2}\right.$-TPR). Determination of chemical and mineral compositions of all samples was done by using Shimadzu EDX-720/800HS Energy Dispersive X-ray Fluorescence Spectrometer (XRF). The changes in the presence of surface functional groups for all samples were investigated using Bruker Optic $\mathrm{GmBH}$ 1997-2000 OPUS Version 3.1 Fourier Transform Infrared Spectrometer (FT-IR). Finally, observation on the reduction behaviour of the catalyst prior to and after calcination step for UCSC and CCSC samples was performed using Thermo Scientific TPDRO 1100 Temperature-Programmed Desorption/Reduction/Oxidation Analyzer.

\section{Results and discussions}

\subsection{Stoichiometric composition of inorganic elements}

Inorganic content in all samples is measured using XRF and is shown in Table 2. As copper and manganese oxides were impregnated onto CSAC, intrinsic potassium and calcium ions were replaced by these metals via ion exchange 
mechanism. After calcination, only small amounts of $\mathrm{Cu}$ can be seen vaporized while slight increase in Mn content is attributed to carbon burn-off. Similar observation was found by Pasel et al. [14] on the loading of copper on activated carbon at various activation temperatures.

Table 2: $\quad$ Stoichiometric composition of inorganic elements in CSAC, UCSC and CCSC.

\begin{tabular}{|l|c|c|c|}
\hline \multirow{2}{*}{ Elements } & \multicolumn{3}{|c|}{ Weight \% (deviation \%) } \\
\cline { 2 - 4 } & & & \\
& CSAC & UCSC & CCSC \\
\hline $\mathrm{K}$ & $69.431(17.5)$ & $1.793(2.3)$ & $6.803(3.4)$ \\
\hline $\mathrm{Ca}$ & $18.862(16.5)$ & $1.193(1.6)$ & $2.057(1.7)$ \\
\hline $\mathrm{Fe}$ & $5.336(7.5)$ & nd & nd \\
\hline $\mathrm{Si}$ & $2.882(24.9)$ & nd & nd \\
\hline $\mathrm{S}$ & $2.033(5.1)$ & $0.648(3.0)$ & $1.346(2.7)$ \\
\hline $\mathrm{Cu}$ & $1.456(4.3)$ & $75.296(8.4)$ & $59.721(5.6)$ \\
\hline $\mathrm{Mn}$ & nd & $21.07(4.4)$ & $30.072(4.0)$ \\
\hline
\end{tabular}

nd: not detectable

By using the same analysis technique (XRF), Thakur et al. [15] concluded that low deviation of elemental weight percentage is related to uniform catalyst dispersion on the surface. From Table 2, loading of $\mathrm{Cu}$ and $\mathrm{Mn}$ using impregnation technique gave a fairly uniform distribution while calcination increased the uniformity of metals loading (4-8\% versus $4-6 \%$ ).

\subsection{Changes in surface functional groups}

Figure 1 illustrates the FT-IR spectra of CSAC, UCSC and CCSC samples. All samples showed adsorption peaks corresponding to stretching vibration of; (1) $\mathrm{OH}$ $\left(3435.89,3436.33\right.$ and $\left.3423.85 \mathrm{~cm}^{-1}\right),(2) \mathrm{NH}=\mathrm{C}(2399.90,2398.33$ and 2393.32 $\left.\mathrm{cm}^{-1}\right),(3) \mathrm{N}=\mathrm{C}\left(1556.90,1551.60\right.$ and $\left.1569.89 \mathrm{~cm}^{-1}\right)$ and (4) C-O (1162.33, 1164.65 and $\left.1161.03 \mathrm{~cm}^{-1}\right)$ [16].

Peak (1) and (4) are oxygenated surface groups, which are also the anchoring sites for metal catalysts [17]. UCSC showed a reduction in these peaks due to the used-up by $\mathrm{Cu}$ and $\mathrm{Mn}$. However after calcination, the absorption peaks reverted which shows $\mathrm{Cu}-\mathrm{Mn}$ ions being vaporized and dispersed more evenly on the other available sites on the CCSC. This is shown by the appearance of adsorption peak corresponding to an in-plane deformation vibration of C-CO at (5) $524.39 \mathrm{~cm}^{-1}$ of CCSC sample [16].

\subsection{Catalyst potential indication}

Primary indication of catalyst potential for SCR reaction with NOx gases can be evaluated from its reduction behavior, which is displayed in Figure 2 for UCSC and CCSC respectively. 


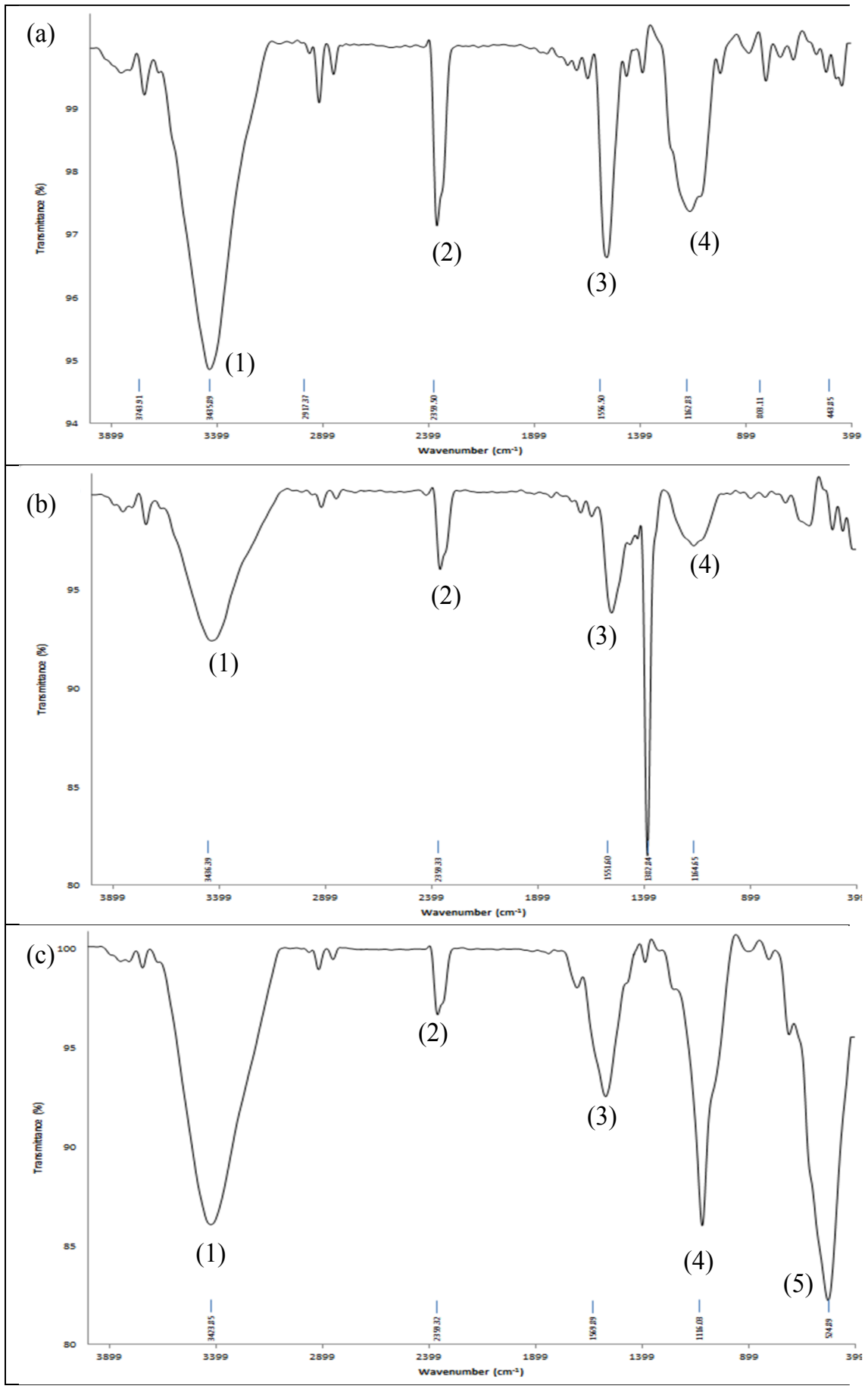

Figure 1: FT-IR spectra of (a) raw CSAC (b) UCSC (c) CCSC. 

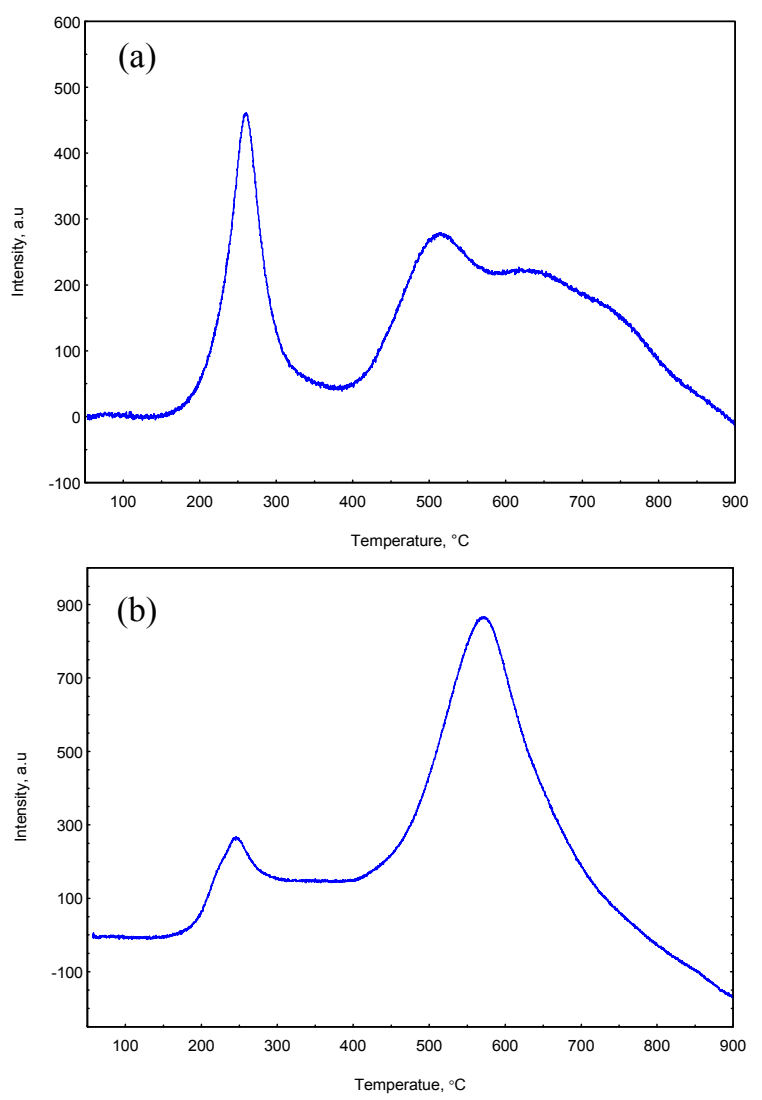

Figure 2: Temperature-programmed Reduction (TPR- $\mathrm{H}_{2}$ ) profile of; (a) UCSC and (b) CCSC.

The peaks at $240-260^{\circ} \mathrm{C}$ indicates the reduction of $\mathrm{CuO}$ while $\mathrm{H}_{2}$-consumption peaks at $500-600^{\circ} \mathrm{C}$ shows the further reduction of $\mathrm{CuO}$ and reduction of $\mathrm{MnO}$ $[17,18]$. It can be observed for CCSC, the intensity of reduction at low temperature decreased and disappearance of shoulder at $\sim 650^{\circ} \mathrm{C}$, which implies that the catalyst has been reduced [19]. It is known that catalyst in its reduced state is reactive in redox reaction [20].

\section{Conclusions}

Besides possessing considerably high surface area, CSAC contains exchangeable cations and intense oxygenated surface functional groups, hence hypothetically can be considered as a suitable candidate for SCR catalyst support. As Cu-Mn was impregnated on CSAC, it can be seen from XRF results that ions exchange had took place. Furthermore, adsorption at oxygenated surface functional groups shown in FT-IR results, aided the metal loading of the catalyst. Subsequently, 
calcination reduced the metals at both low and high temperatures. Based on these results, CSAC has a high potential to be developed as SCR catalyst for reduction of NOx gases. Future investigation is recommended to observe the uniformity and stability of metals loading.

\section{Acknowledgements}

The authors wish to acknowledge University Malaysia Sarawak for supporting this work under the RAGS/TK/05(1)/940/2012(41) grant and Universiti Putra Malaysia for the analysis works.

\section{References}

[1] Canadian Centre for Energy Information (2013) Biomass History, 09-Oct2012, http://www.centreforenergy.com/AboutEnergy/Biomass/History.asp.

[2] Xu, C.C., Donald, D., Byambajav, E. \& Ohtsuka, Y. (2010) Recent advances in catalysts for hot-gas removal of tar and $\mathrm{NH}_{3}$ from biomass gasification. Fuel 89 (1784-1795).

[3] Mohammed, M.A.A., Salmiaton, A., Wan Azlina, W.A.K.G., Mohammad Amran, M.S., Fakhru'l-Razi, A. \& Taufiq-Yap, Y.H. (2011) Hydrogen rich gas from oil palm biomass as a potential source of renewable energy in Malaysia. Renewable and Sustainable Energy Reviews 15 (1258-1270).

[4] Peterson, D. \& Haase, S. (2009) Market assessment of biomass gasification and combustion technology for small- and medium-scale applications. Technical report for National Renewable Energy Laboratory, USA (NREL/TP-7A2-46190).

[5] Perry, R.H. \& Green, D.W. (1999) Perry's Chemical Engineers' Handbook. McGraw Hill: USA.

[6] Benson, S.A., Laumb, J.D., Crocker, C.R. \& Pavlish, J.H. (2005) SCR catalyst performance in flue gases derived from subbituminous and lignite coals. Fuel Processing Technology 86 (577-613).

[7] Kubinski, D.J. \& Visser, J.H. (2008) Sensor and method for determining the ammonia loading of a zeolite SCR catalyst. Sensors \& Actuators B 130 (425-429).

[8] Wang, L., Liu, Z., Li, P., Yu, J. \& Rodrigues, A.E. (2012) Experimental and modeling investigation on post-combustion carbon dioxide capture using zeolite 13X-APG by hybrid VTSA process. Chemical Engineering Journal 197 (151-161).

[9] Shang, X., Hu, G., He, C., Zhao, J., Zhang, F., Xu, Y., Zhang, Y., Li, J. \& Chen, J. (2012) Regeneration of full-scale commercial honeycomb monolith catalyst (V2O5-WO3/TiO2) used in coal-fired power plant. Journal of Industrial and Engineering Chemistry 18 (513-519).

[10] Yang, Y., Chiang, K. \& Burke, N. (2011) Porous carbon-supported catalyst for energy and environmental applications: A short review. Catalysis Today $178(197-205)$. 
[11] Guo, X., Bartholomew, C., Hecker, W. \& Baxter, L.L. (2009) Effects of sulfate species on V2O5/TiO2 SCR catalyst in coal and biomass-fired systems. Applied Catalysis B: Environmental 92 (30-40).

[12] Putluru, S.S.R., Riisager, A. \& Fehrmann, R. (2011) Alkali resistant $\mathrm{Cu} /$ zeolite deNOx catalyst for flue gas cleaning in biomass fired applications. Applied Catalysis B: Environmental 101 (183-188).

[13] Singh, S., Nahil, M.A., Sun, X., Wu, C., Chen, J., Shen, B. \& Williams, P.T. (2012) Novel application of cotton stalk as a waste derived catalyst in the low temperature SCR-deNOx process. In corrected for proof in Fuel (1-10).

[14] Pasel, J., Kabner, P., Montanari, B., Gazzano, M., Vaccari, A., Makowski, W., Lojewski, T., Dziembaj, R. \& Papp, H. (1998) Transition metal oxides supported on active carbons as low temperature catalysts for the selective catalytic reduction (SCR) of $\mathrm{NO}$ with $\mathrm{NH}_{3}$. Applied Catalysis B: Environmental 18 (199-213).

[15] Thakur, D.B., Tiggelaar, R.M., Gardeniers, J.G.E., Lefferts, L. \& Seshan, K. (2012) Silicon based microreactors for catalytic reduction in aqueous phase: Use of carbon nanofiber supported palladium catalyst. In corrected for proof in Chemical Engineering Journal.

[16] FTIR Wizard (2013), 10-Nov-2013, http://www.science-and-fun.de/cgibin/irwiz-more2.pl.

[17] Martins, L., Peguin, R.P.S. \& Urquieta-Gonzalez, E.A. (2006) Cu and Co exchanged ZSM-5 Zeolites - Activity towards NO reduction and hydrocarbon oxidation, Quimica Nova 29 (223-229).

[18] Li, J., Chang, H., Ma, L., Hao, J. \& Yang, R.T. (2011) Low-temperature selective catalytic reduction of NOx with NH3 over metal oxide and zeolite catalysts - A review. Catalysis Today 175 (147-156).

[19] Huang, B., Huang, R., Jin, D. \& Ye, Daiqi (2007) Low temperature SCR of NO with NH3 over carbon nanotubes supported vanadium oxides. Catalysis Today 126 (279-283).

[20] Nejar, N., Garcia-Cortes, J.M., Salinas-Martinez, C.L. \& Illan-Gomez, M.J. (2005) Bimetallic catalysts for the simultaneous removal of NOx and soot from diesel engine exhaust: A preliminary study using intrinsic catalysts. Catalysis Communication 6 (263-267). 